\title{
Thermoelectric Power and Magnetic Susceptibility of Liquid Silver Alloys
}

\author{
By M. Matsuura* and S. Takeuchi**
}

\begin{abstract}
The thermoelectric power and the magnetic susceptibility have been measured on the liquid silver alloys of $\mathrm{Ag}-\mathrm{In}, \mathrm{Ag}-\mathrm{Sn}, \mathrm{Ag}-\mathrm{Pb}, \mathrm{Ag}-\mathrm{Bi}$ and $\mathrm{Ag}-\mathrm{Sb}$ systems over a wide temperature ranges of about 500 to $1000^{\circ} \mathrm{C}$.

The magnetic susceptibility curves at about $1000^{\circ} \mathrm{C}$ plotted against the alloy compositions are almost linear for liquid $\mathrm{Ag}-\mathrm{Pb}$ and $\mathrm{Ag}-\mathrm{Bi}$ alloys, but show a diamagnetic increase in the composition range of $85 \%$ to $70 \% \mathrm{Ag}$ in other silver alloys.

The thermoelectric power varies in a relatively simple way with the alloy compositions for the liquid alloys except for the liquid $\mathrm{Ag}-\mathrm{Sb}$ alloys which behave in a remarkably anomalous way with a sharp minimum at about $10 \% \mathrm{Sb}$ and a broad maximum at about $35 \% \mathrm{Sb}$.

Calculations based on the assumption of random mixing of constituent atoms in these liquid alloys are performed for the magnetic susceptibility and the thermoelectric power. It is shown that the calculated results are in good agreement with the measurements for the liquid $\mathbf{A g}-\mathrm{Pb}$ and $\mathrm{Ag}-\mathrm{Bi}$ alloys but are different from the experimental results for the other silver alloys. These facts suggest that contributions to these physical properties by the formation of "pseudomolecules" cannot be neglected in the liquid silver alloys except in liquid $\mathrm{Ag}-\mathrm{Pb}$ and $\mathrm{Ag}-\mathrm{Bi}$ alloys.
\end{abstract}

(Received January 29, 1976)

\section{Introduction}

It has been found that liquid copper alloys have very interesting features in the thermodynamical, electronic and structural properties. On mixing the liquid copper with the liquid bismuth $^{(1)}$ or the liquid lead ${ }^{(2)}$, the absorption of heat is observed and its amount varies parabolically with the concentration of alloying elements. The magnetic susceptibility ${ }^{(3)}$ and Hall coefficient ${ }^{(1)}$ of these liquid alloys change monotonically with the alloy composition. Accordingly, it is considered that in the liquid $\mathrm{Cu}-\mathrm{Bi}$ and $\mathrm{Cu}-\mathrm{Pb}$ alloys the ions are randomly arranged in the atmosphere of the conduction electron gas. But the heat of mixing of the other copper alloys such as $\mathrm{Cu}-\mathrm{In}, \mathrm{Cu}-\mathrm{Sn}$ and $\mathrm{Cu}-\mathrm{Sb}^{(1)}$ gives the evolution of heat, which has a sharp maximum in the composition range of

* The Research Institute for Iron, Steel and Other Metals, Tohoku University, Sendai. Present address: Miyagi Technical College, Natori 981-12, Japan.

** The Research Institute for Iron, Steel and Other Metals, Tohoku University, Sendai. Present address: Muroran Institute of Technology, Muroran 050, Japan.

Trans. JIM
$75 \%$ to $85 \% \mathrm{Cu}$. The magnetic susceptibility ${ }^{(3)}$ of these liquid alloys shows a diamagnetic increase in the same composition range as that mentioned above. These anomalous behaviors in thermodynamical and magnetic properties can be understood by taking account of the formation of the pseudomolecule. The pseudomolecule is a sort of cluster, which consists of several atoms of the composition such as $\mathrm{Cu}_{3} \mathrm{In}$, for example, in the liquid $\mathrm{Cu}$-In alloy. The number of localized electrons for binding atoms in the pseudomolecule is considered to be only about two near the temperature of $1000^{\circ} \mathrm{C}$ and, therefore, it has a flexible structure which is different from a real molecule with a rigid structure. The Hall coefficients of the liquid alloys $\mathrm{Cu}-\mathrm{In}, \mathrm{Cu}-\mathrm{Sn}$ and $\mathrm{Cu}-\mathrm{Sb}$ calculated by taking the formation of the pseudomolecule into account are in good agreement with the experimental results ${ }^{(4)}$.

Liquid silver alloys have the similar behaviors for the heat of mixing ${ }^{(5)(6)}$ as that in the liquid copper alloys. We have dealt with the liquid silver alloys to investigate the effects of pseudomolecules on the thermoelectric power and the magnetic susceptibility.

The thermoelectric power of liquid alloys of the noble metals have scarcely ever been 
measured except for the liquid alloys $\mathrm{Cu}-\mathrm{Sn}^{(7)}$ and $\mathrm{Ag}-\mathrm{Au}^{(8)}$. In this paper the thermoelectric power and magnetic susceptibility are measured for liquid alloys of $\mathrm{Ag}-\mathrm{In}, \mathrm{Ag}-\mathrm{Sn}, \mathrm{Ag}-\mathrm{Pb}$, $\mathrm{Ag}-\mathrm{Bi}$ and $\mathrm{Ag}-\mathrm{Sb}$ systems.

As the first step for the investigation on the effects of the pseudomolecule, the experimental results are discussed under the assumption of random mixing of ions of liquid alloys in the gas atmosphere of the conduction electrons.

\section{Measurement of Thermoelectric Power and Magnetic Susceptibility}

The experimental method for measuring the thermoelectric power is similar to that performed by Marwaha ${ }^{(9)}$. A quartz capillary tube $200 \mathrm{~mm}$ in length and $2 \mathrm{~mm}$ in diameter is used for a liquid alloy container. As shown in Fig. 1 the copper electrodes and the thermocouples are welded on the thin tungsten foils which contact with the liquid sample through the two holes at the upper and lower parts of the capillary tube. The temperature of the liquid at the lower hole is kept constant $T_{1}$ and that at the upper hole $\left(T_{2}\right)$ is changed continuously. The thermoelectric voltage is obtained as a

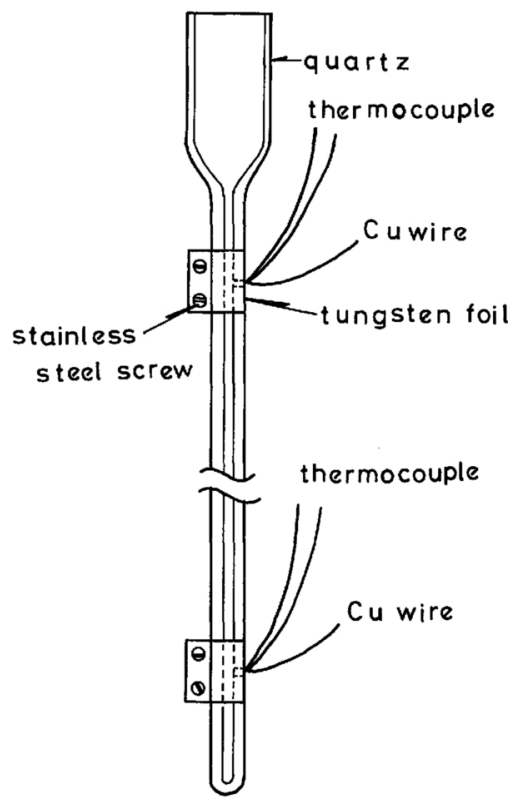

Fig. 1 The apparatus used for the measurement of the thermoelectric power of the liquid metals. function of temperature at the upper hole.

The liquid samples are prepared by melting the constituent metals of high purity in vacuum to remove gas contained in metals prior to the measurement. The composition of samples is checked by the chemical analysis after each measurement.

The thermoelectric voltage of the liquid alloys is obtained by subtracting that of solid copper electrode from the measured voltage. The voltage of the solid copper determined by Cusack and Kendall ${ }^{(10)}$ is used as the standard. Experimental error in these measurements is at most $\pm 1.0 \mu \mathrm{V} / \mathrm{deg}$.

The measurements of the magnetic susceptibility of liquid alloys are made by the usual torsion balance method at the temperature near $1000^{\circ} \mathrm{C}$.

Errors in the measurement of the magnetic susceptibility are estimated to be within $\pm 5 \%$.

\section{Experimental Results}

The temperature dependence of the observed thermo e.m.f $(\mathrm{mV})$ of the pure liquid In and the liquid Ag-In alloys as a function of the temperature between the upper and lower holes is shown in Fig. 2. The curves of thermo e.m.f vs temperature are expressed by the following

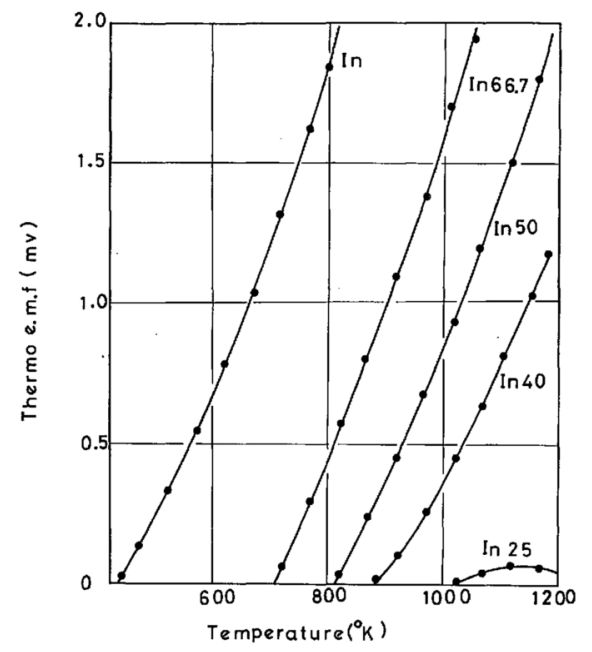

Fig. 2 Thermo. e.m.f vs temperature relative to solid copper for the liquid In and $\mathrm{Ag}$-In alloy. The solid line is an approximation to $E=a+b T+$ $c T^{2}$ by the least squares method. 
equation:

$$
E=a+b T+c T^{2}
$$

The thermoelectric power $S$ is derived from

$$
S-S_{0}=(d E / d T)_{T_{2}},
$$

where $S_{0}$ is the value of the thermoelectric power of solid copper.

The observed temperature variations of the thermoelectric power $S$ of liquid metals $\mathrm{Ag}$, In, $\mathrm{Sn}, \mathrm{Pb}, \mathrm{Sb}$ and $\mathrm{Bi}$ obtained by the above method are shown in Fig. 3 together with the observed results by Marwaha and Cusack ${ }^{(11)}$, Howe and Enderby ${ }^{(8)}$ and Blakeway ${ }^{(12)}$. The present results are in good agreement with those of the above authors within experimental errors. Figures 4 and 5 show the temperature dependence of $S$ values for various compositions of liquid $\mathrm{Ag}-\mathrm{In}$ and $\mathrm{Ag}-\mathrm{Sb}$ alloys. In the case of $\mathrm{Ag}$-In alloy, the $S$ value for each concentration of In is decreased with increase in temperature, and the same behaviors are observed in other many alloys. But it is observed in the liquid $\mathrm{Ag}-\mathrm{Sb}$ alloys that the $S$ value has a positive temperature dependence in the composition range of more than $40 \% \mathrm{Sb}$.

The composition dependence of the thermoelectric power $S$ at $980^{\circ} \mathrm{C}$ is shown in the curves

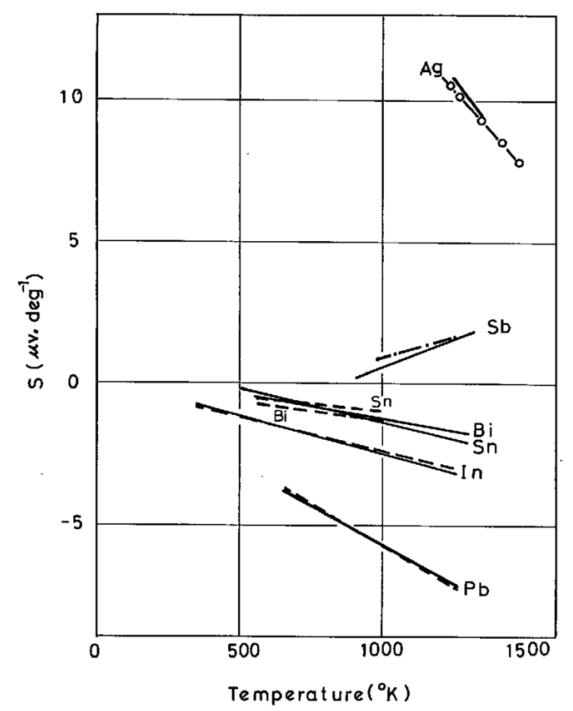

Fig. 3 Thermoelectric power vs temperature for the liquid metals. —_ ; present work, - -

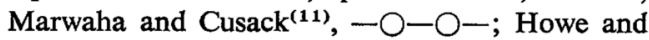
Enderby $^{(8)}$, - - - B Blakeway ${ }^{(12)}$.

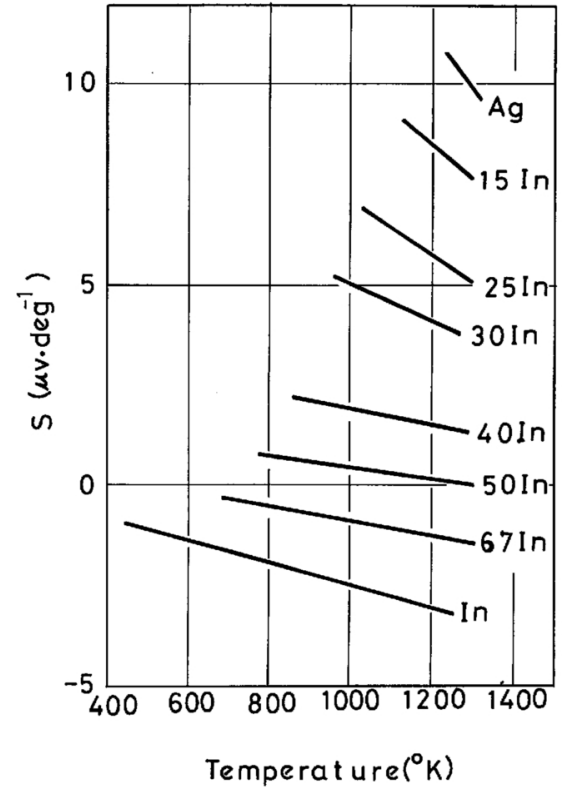

Fig. 4 Thermoelectric power vs temperature of liquid $\mathrm{Ag}$-In alloys.

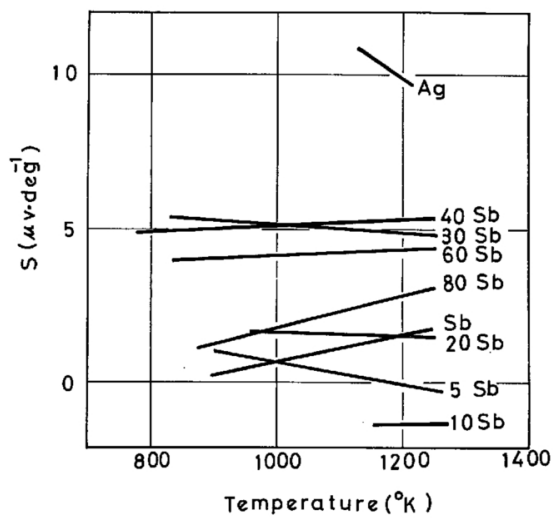

Fig. 5 Thermoelectric power vs temperature of liquid $\mathrm{Ag}-\mathrm{Sb}$ alloys.

in Fig. 6 for the liquid alloys of $\mathrm{Ag}-\mathrm{In}, \mathrm{Ag}-\mathrm{Sn}$, $\mathrm{Ag}-\mathrm{Pb}, \mathrm{Ag}-\mathrm{Bi}$ and $\mathrm{Ag}-\mathrm{Sb}$ systems. It is evident from Fig. 6 that the thermoelectric powers $S$ of these liquid alloys of $\mathrm{Ag}$ decrease generally with the concentration of alloying elements added to $\mathrm{Ag}$, but for the liquid $\mathrm{Ag}-\mathrm{Sb}$ alloys it behaves in a different way from the other alloys. The $S$ value of liquid $\mathrm{Ag}-\mathrm{Sb}$ alloy decreases markedly with increasing Sb content to a minimum value of $10 \% \mathrm{Sb}$ and then increases to a maximum value of about $35 \%$ $\mathrm{Sb}$, followed by a monotonous decrease. 


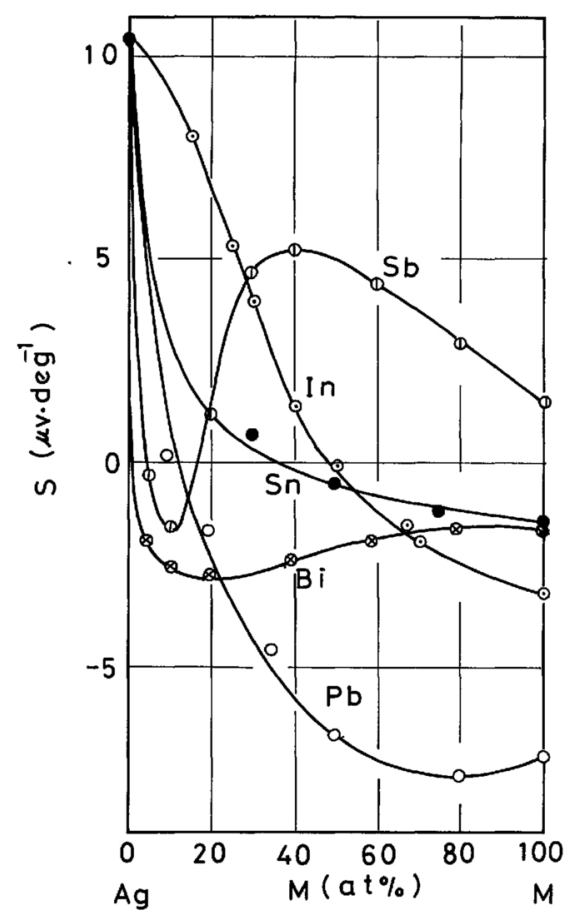

Fig. 6 Thermoelectric power vs concentration of liquid $\mathrm{Ag}-\mathrm{In}, \mathrm{Ag}-\mathrm{Sn}, \mathrm{Ag}-\mathrm{Sb}, \mathrm{Ag}-\mathrm{Pb}$ and $\mathrm{Ag}-\mathrm{Bi}$ alloys at $980^{\circ} \mathrm{C}$.

Figures 7, 8, 9, 10 and 11 show the variations in magnetic susceptibility at $1000^{\circ} \mathrm{C}$ with composition for liquid alloys $\mathrm{Ag}-\mathrm{Pb}, \mathrm{Ag}-\mathrm{Bi}, \mathrm{Ag}-\mathrm{In}$, $\mathrm{Ag}-\mathrm{Sn}$ and $\mathrm{Ag}-\mathrm{Sb}$, respectively. The temperature coefficients of magnetic susceptibility in these liquid alloys are very small and within

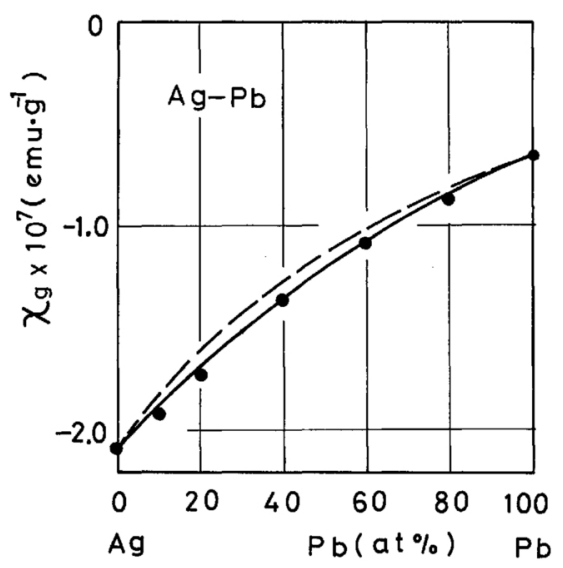

Fig. 7 Magnetic susceptibility vs concentration of liquid $\mathrm{Ag}-\mathrm{Pb}$ alloys at $1000^{\circ} \mathrm{C}$. Broken line indicates the calculated value by the nearly free electron model.

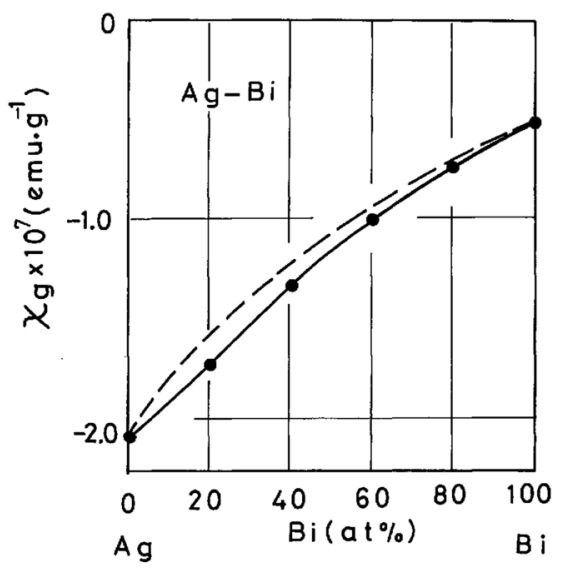

Fig. 8 Magnetic susceptibility vs concentration of liquid $\mathrm{Ag}-\mathrm{Bi}$ alloys at $1000^{\circ} \mathrm{C}$. Broken line indicates the calculated value by the nearly free electron model.

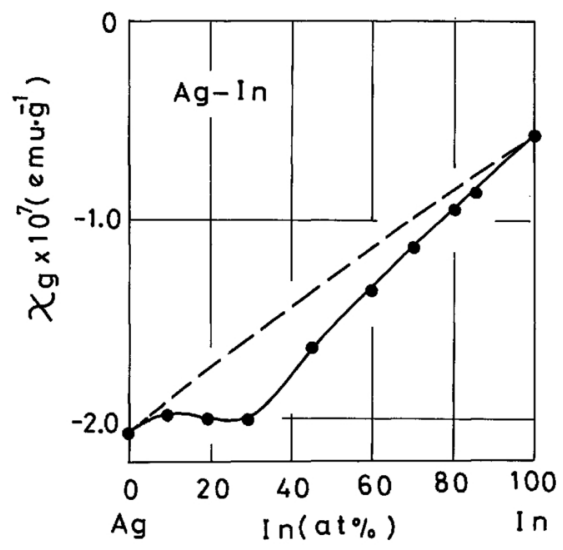

Fig. 9 Magnetic susceptibility vs concentration of liquid $\mathrm{Ag}$-In alloys at $1000^{\circ} \mathrm{C}$. Broken line indicates the calculated value by the nearly free electron model.

$0.5 \times 10^{-10} \mathrm{emu} / \mathrm{g}$ per degree. In the case of the liquid $\mathrm{Ag}-\mathrm{Bi}$ and $\mathrm{Ag}-\mathrm{Pb}$ alloys the susceptibility shows a monotonous change with increase in concentration, but in the cases of $\mathrm{Ag}-\mathrm{In}$, $\mathrm{Ag}-\mathrm{Sn}$ and $\mathrm{Ag}-\mathrm{Sb}$ alloys it exhibits a diamagnetic increase in the concentration range of $60 \%$ to $90 \% \mathrm{Ag}$. Such a diamagnetic increase has also been observed in the liquid $\mathrm{Cu}-\mathrm{In}, \mathrm{Cu}-\mathrm{Sn}$ and $\mathrm{Cu}-\mathrm{Sb}$ alloys.

\section{Simple Theory of Thermoelectric Power and Magnetic Susceptibility for Liquid Alloys}

As the first step to explain the experimental 


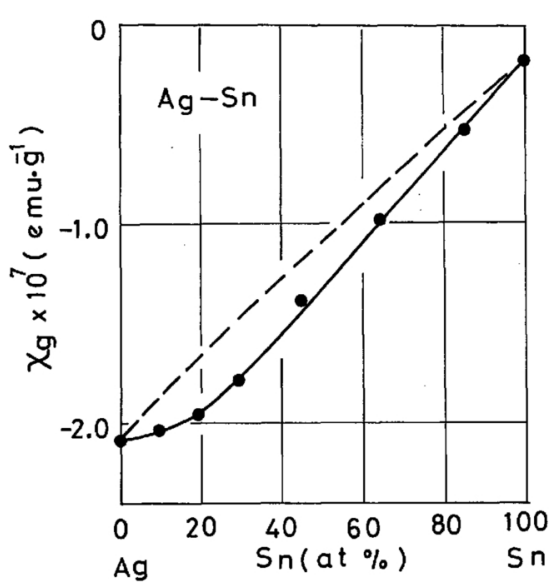

Fig. 10 Magnetic susceptibility vs concentration of liquid $\mathrm{Ag}-\mathrm{Sn}$ alloys at $1000^{\circ} \mathrm{C}$. Broken line indicates the calculated value by the nearly free electron model.

results, calculations for the thermoelectric power $S$ and magnetic susceptibility $\chi$ have been performed by a simple theory based on the assumption that the constituent ions in a liquid alloy are randomly arranged in a gas atmosphere of conduction electrons. In the forthcoming paper ${ }^{(13)}$ the calculations taking account of the pseudomolecule will be developed.

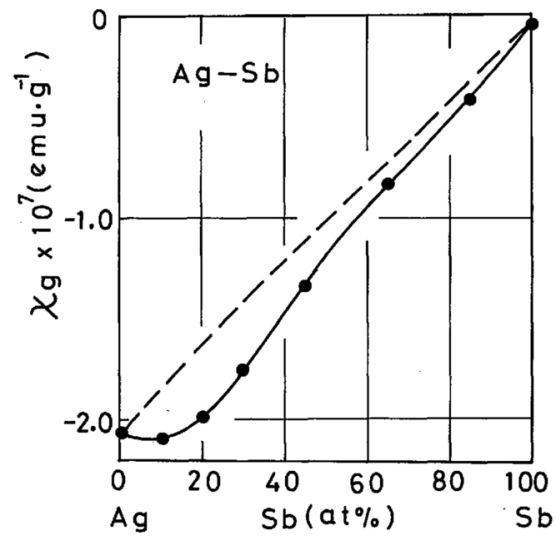

Fig. 11 Magnetic susceptibility vs concentration of liquid $\mathrm{Ag}-\mathrm{Sb}$ alloys at $1000^{\circ} \mathrm{C}$. Broken line indicates the calculated value by the nearly free electron model.

\section{Thermoelectric power $S$}

It is convenient to use a dimensionless parameter $\xi$ instead of the thermoelectric power $S$. $\xi$ is defined as

$$
\xi=-S \frac{3 e}{\pi^{2}} \frac{E_{F}}{k^{2} T}=-E_{F}\left[\frac{\partial \log \rho(E)}{\partial E}\right]_{E=E_{F}},
$$

where $E_{F}$ denotes the Fermi energy and $\rho(E)$ the electrical resistivity obtained as a function

of the energy of conduction electrons.

Thermoelectric parameter $\xi$ is given from Ziman's formula ${ }^{(14)}$ as follows:

$$
\xi=3-2 q-\frac{1}{2} r
$$

where

$$
q=\frac{\left|u\left(K / 2 k_{F}\right)\right|_{k=2 k_{F}}^{2} \cdot a\left(K / 2 k_{F}\right)}{\int_{0}^{1}\left|u\left(K / 2 k_{F}\right)\right|^{2} \cdot a\left(K / 2 k_{F}\right) \cdot\left(K / 2 k_{F}\right)^{3} d\left(K / 2 k_{F}\right)},
$$

and

$$
r=\frac{\left.k_{F} \int_{0}^{1}|\partial| u\left(K / 2 k_{F}\right)\right|^{2} /\left.\partial k\right|_{k=k_{F}} \cdot a\left(K / 2 k_{F}\right) \cdot\left(K / 2 k_{F}\right)^{3} d\left(K / 2 k_{F}\right)}{\int_{0}^{1}\left|u\left(K / 2 k_{F}\right)\right|^{2} \cdot a\left(K / 2 k_{F}\right) \cdot\left(K / 2 k_{F}\right)^{3} d\left(K / 2 k_{F}\right)} .
$$

$u\left(K / 2 k_{F}\right)$ is a pseudopotential form factor and $a\left(K / 2 k_{F}\right)$, an interference function. In the case of binary alloy $\left|u\left(K / 2 k_{F}\right)\right|^{2} \cdot a\left(K / 2 k_{F}\right)$ is rewritten by Faber-Ziman ${ }^{(15)}$ as follow:

$$
\begin{aligned}
\left|u\left(K / 2 k_{F}\right)\right|^{2} \cdot a\left(K / 2 k_{F}\right)= & u_{1}^{2}\left[c_{1}\left(1-c_{1}\right)+c_{1}^{2} a_{11}\right]+u_{2}^{2}\left[c_{1}\left(1-c_{1}\right)+\left(1-c_{1}\right)^{2} a_{22}\right] \\
& +2 u_{1} u_{2} c_{1}\left(1-c_{1}\right)\left(a_{12}-1\right),
\end{aligned}
$$

where $c_{1}$ is the atomic fraction of component $1, a_{11}, a_{12}$ and $a_{22}$ are the partial interference functions, which can be calculated under the above assumption of random mixing of binary hard spheres with different diameters. As the pseudopotential for usual simple metals the empty core potential proposed by Ashcroft ${ }^{(16)}$ is useful but it is inappropriate for 
Table 1 Pseudopotential parameters used for the calculation of the thermoelectric power of liquid silver alloys. $R_{c}$ is the empty core radius in $\AA$ and $\partial \ln R_{c} / \partial \ln E$ its energy derivative in $\AA \mathrm{Ryd}^{-1}$.

\begin{tabular}{ccccccc}
\hline & $\mathrm{In}$ & $\mathrm{Sn}$ & $\mathrm{Pb}$ & $\mathrm{Sb}$ & $\mathrm{Bi}$ & $\mathrm{Ag} *$ \\
\hline$R_{c}$ & 0.73 & 0.735 & 0.81 & 0.766 & 0.825 & 2.39 \\
$\partial \ln R_{c} / \partial \ln E$ & -0.245 & -0.076 & -0.308 & 0.124 & -0.807 & -0.660 \\
\hline
\end{tabular}

* $R_{c}$ value for $\mathrm{Ag}$ indicates $r_{2}$ in eq. (6).

the noble metal Ag. Several kinds of pseudopotential for the noble metal have been proposed by Moriarty ${ }^{(17)}$, Borchi and Gennaro ${ }^{(18)}$, Dreirach et al. ${ }^{(19)}$, Cubiotti et al. ${ }^{(20)}$ and Animalu $^{(21)}$. In this paper, we employ the pseudopotential containing adjustable parameters proposed by Borchi and Gennaro. It has following properties such as

$$
\left.\begin{array}{ll}
V(r)=0 & 0<r<r_{1} \\
V(r)=-A & r_{1}<r<r_{2} \\
V(r)=-Z e^{2} / r & r_{2}<r
\end{array}\right\},
$$

where a parameter $r_{1}$ corresponds to the core radius, taking as $r_{1}=1$ a.u. and $-A$ is the depth of the square well potential due to $s-d$ hybridization. Adjustable parameters $A$ and $r_{2}$ are chosen to give the best fitting to the observations of physical properties concerning the pure liquid $\mathrm{Ag}$ and the liquid $\mathrm{Ag}$ alloy. In the case of liquid $\mathrm{Ag}-\mathrm{Pb}$ alloy ions $\mathrm{Ag}^{+1}$ and $\mathrm{Pb}^{+4}$ are considered to be randomly distributed in the gas atmosphere of conduction electrons from the observed curves of heat of mixing $^{(6)}$ and magnetic susceptibility vs compositions. Therefore, the interference function $a(k)$ of the liquid $\mathrm{Ag}-\mathrm{Pb}$ alloy can be calculated using the model of the binary mixture of the hard spheres with different diameters. The above parameters $A$ and $r_{2}$ have been determined by comparison with the electrical resistivity $\rho$, which is calculated by using eq. (5):

$$
\rho=\frac{2 \pi m^{2} N}{\hbar^{3} e^{2} \Omega k_{F}^{2}}\left\langle\left|u\left(K / 2 k_{F}\right)\right|^{2} \cdot a\left(K / 2 k_{F}\right)\right\rangle
$$

with the observed resistivity of the pure liquid $\mathrm{Ag}$ and the liquid $\mathrm{Ag}-\mathrm{Pb}$ alloy ${ }^{(22)}$. The pseudopotential parameters of $\mathrm{Ag}$ determined by the above method are given by

$$
A=0.6 \mathrm{Ry} \text {. and } r_{2}=2.39 \AA .
$$

The core radius parameter $R_{\text {core }}$ in the Ashcroft potential used for the other simple metals is determined from the observed electrical resistivity of each pure liquid metal. The pseudopotential parameters of several metals used for the calculation of the thermoelectric power $S$ are listed in Table 1.

Next, we must evaluate the terms $q$ and $r$ in eq. (2) to obtain $\xi$. The term $q$ can be easily calculated from the form factor $u\left(K / 2 k_{F}\right)$ and structure factor $a(k)$, but the energy derivative of the pseudopotential is included in the term $r$ as seen from eq. (4). This may be considered to be reduced to $\left(\partial \log R_{\text {core }} / \partial \log k\right)$, which can be determined from the experimental value of the thermoelectric power of the pure liquid metal. The value $\left(\partial \log R_{\text {core }} / \partial \log k\right)$ thus determined is shown in Table 1 . By the method described above, the thermoelectric power $S$ has been calculated for several liquid silver alloys. These results are shown in Figs. 12, 13, 14,15 and 16 for the liquid alloys $\mathrm{Ag}-\mathrm{Pb}$, $\mathrm{Ag}-\mathrm{Bi}, \mathrm{Ag}-\mathrm{In}, \mathrm{Ag}-\mathrm{Sn}$ and $\mathrm{Ag}-\mathrm{Sb}$, respectively.

The calculated curves for the liquid alloys $\mathrm{Ag}-\mathrm{Pb}$ and $\mathrm{Ag}-\mathrm{Bi}$, in which the constituent atoms are randomly distributed, are in fairly good agreement with the experimental curves. But, the calculated results for the other liquid alloys $\mathrm{Ag}-\mathrm{In}, \mathrm{Ag}-\mathrm{Sn}$ and $\mathrm{Ag}-\mathrm{Sb}$ do not agree with the experimental results.

\section{Magnetic susceptibility}

The total magnetic susceptibility of a liquid metal can be generally given by the sum of the diamagnetic susceptibility due to the ions and the paramagnetic susceptibility due to the conduction electrons. Hence, the total magnetic susceptibility per mole of a liquid alloy is written as

$$
\chi=\chi_{e}+(1-x) \chi_{i A}+x \chi_{i B},
$$

where $\chi_{i A}$ and $\chi_{i B}$ are the diamagnetic sus- 


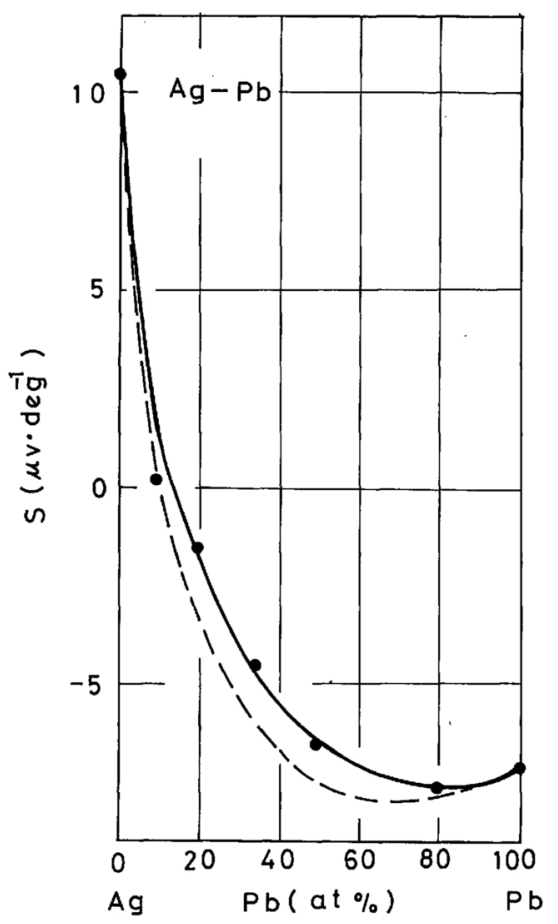

Fig. 12 Thermoelectric power vs concentration for liquid $\mathrm{Ag}-\mathrm{Pb}$ alloys at $980^{\circ} \mathrm{C}$. Broken line indicates calculated value.

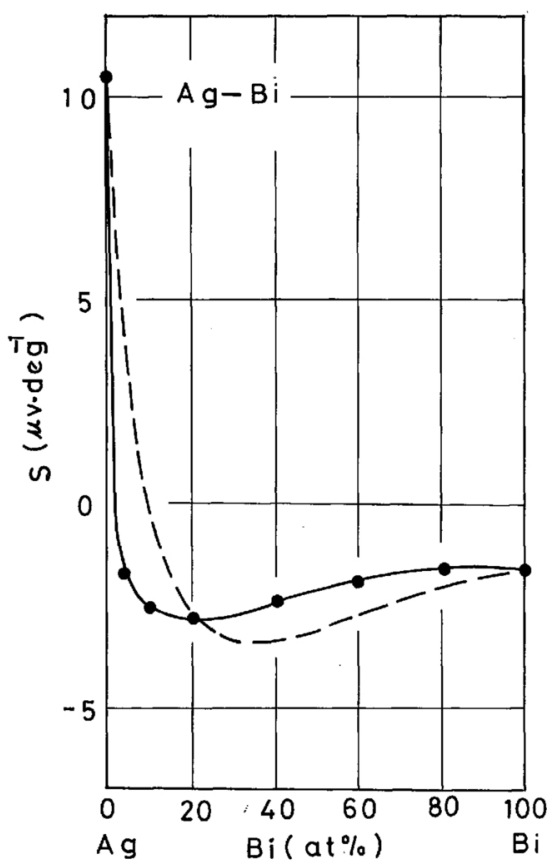

Fig. 13 Thermoelectric power vs concentration for liquid $\mathrm{Ag}-\mathrm{Bi}$ alloys at $980^{\circ} \mathrm{C}$. Broken line indicates the calculated value.

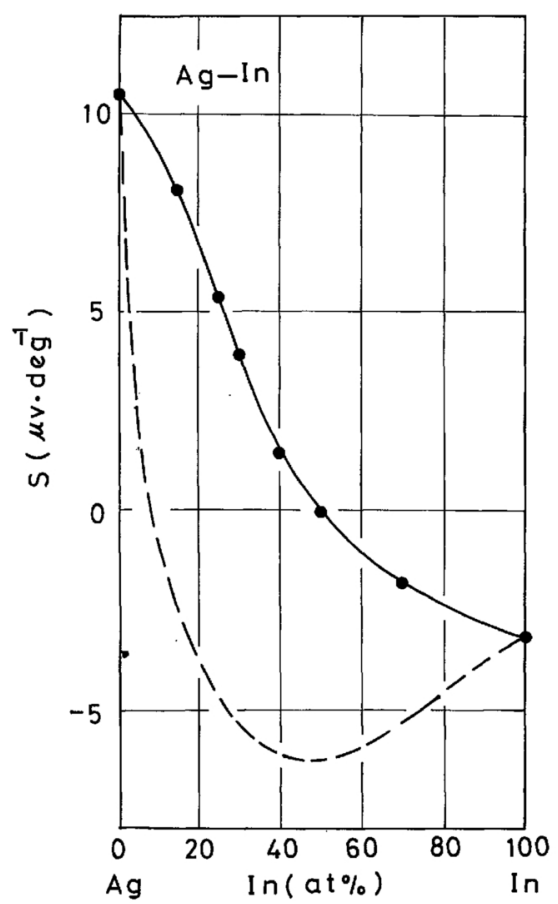

Fig. 14 Thermoelectric power vs concentration for liquid $\mathrm{Ag}-\mathrm{In}$ alloys at $980^{\circ} \mathrm{C}$. Broken line indicates the calculated value.

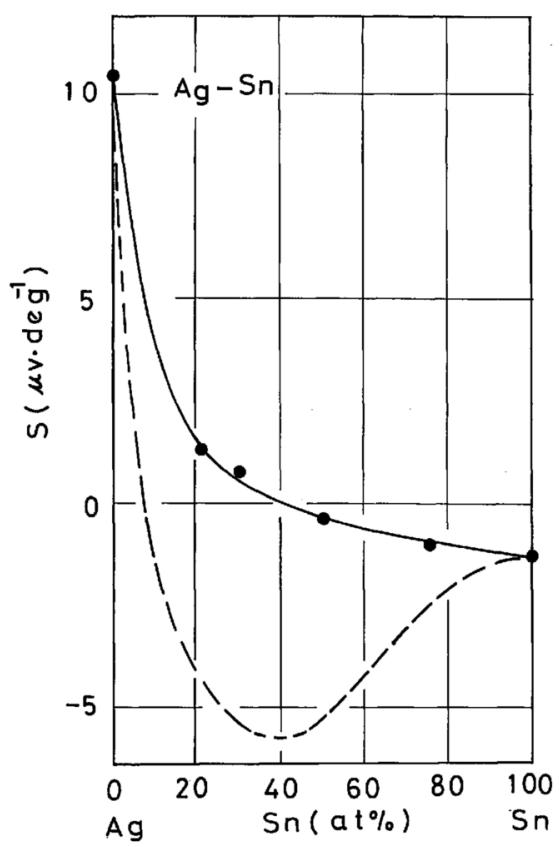

Fig. 15 Thermoelectric power vs concentration for liquid $\mathrm{Ag}-\mathrm{Sn}$ alloys at $980^{\circ} \mathrm{C}$. Broken line indicates the calculated value. 


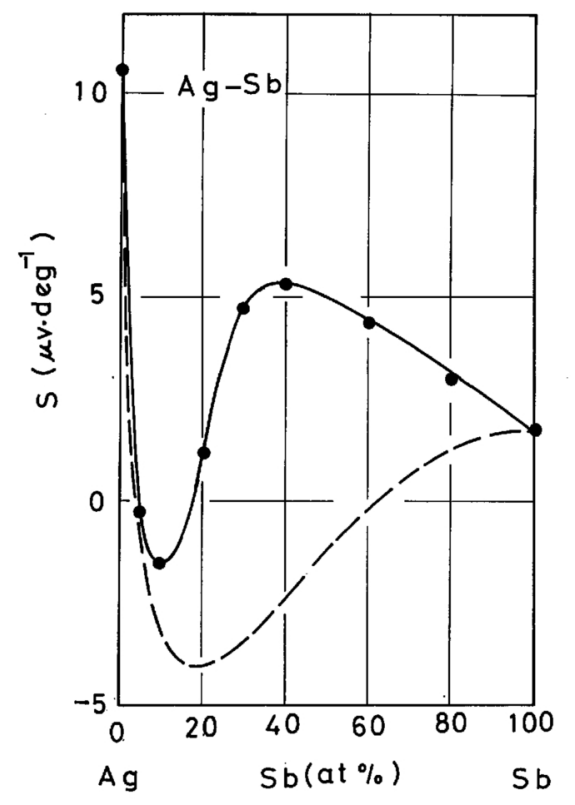

Fig. 16 Thermoelectric power vs concentration for liquid $\mathrm{Ag}-\mathrm{Sb}$ alloys at $980^{\circ} \mathrm{C}$. Broken line indicates the calculated value.

ceptibility due to the ions $A$ and $B$, respectively and $x$ atomic fraction of $B$ ion. $\chi_{e}$ denotes the Landau diamagnetism and the Pauli paramagnetism due to the conduction electrons in one mole of an alloy. $\chi_{e}$ is written as

$$
\chi_{e}=1.246 \times 10^{-6}(\bar{A})^{2 / 3}(\bar{Z})^{1 / 3} d^{-2 / 3}
$$

and

$$
\bar{A}=(1-x) M_{A}+x M_{B},
$$

where $\bar{A}$ is the mean atomic weight of an alloy, $d$ the density, $\bar{Z}$ the mean number of valence electrons per atom and $M$ the atomic weight of the alloy components. Since the observed susceptibility is given by the terms of unit mass $\chi_{g}, \chi$ in the above equation must be changed into $\chi_{g}$ as follows:

$$
\chi_{g}=\frac{\chi_{e}}{\bar{A}}+(1-x) \frac{M_{A}}{\bar{A}} \chi_{i A}^{g}+x \frac{M_{B}}{\bar{A}} \chi_{i B}^{g},
$$

where $\chi^{g}$ is the diamagnetic susceptibility of ions per unit mass. $\chi_{i A}^{g}$ and $\chi_{i B}^{g}$ for elementary components $A$ and $B$ of an alloy measured by different authors fluctuate over a wide range, so in this paper the diamagnetic susceptibility of ions $A$ and $B$ are given by those obtained by subtracting the calculated susceptibility of the conduction electrons from the observed total magnetic susceptibility of the respective pure liquids. Using these $\chi_{i A}^{q}$ and $\chi_{i B}^{q}$ the composition dependence of $\chi_{g}$ for the liquid Ag alloys can be calculated from eq. (8). In the case of the liquid $\mathrm{Ag}-\mathrm{Pb}$ and $\mathrm{Ag}-\mathrm{Bi}$ alloys, the calculated curves given by broken lines in Figs. 7 and 8 are in good agreement with the observation. In the other alloys, however, the calculated curves are remarkably different from the experimental results as shown in Figs. 9, 10 and 11.

\section{Discussion}

For the liquid $\mathrm{Ag}-\mathrm{Bi}$ and $\mathrm{Ag}-\mathrm{Pb}$ alloys the calculated results on the thermoelectric power and the magnetic susceptibility are in good agreement with the observations. The structure of the liquid $\mathrm{Ag}-\mathrm{Bi}$ and $\mathrm{Ag}-\mathrm{Pb}$ alloys, therefore, can be approximated by the model in which the constituent ions are randomly distributed in the electron gas atmosphere. Such a model can also be supported by the experimental results on the heat of mixing for those liquid alloys: the absorption of heat is observed on mixing the constituent atoms in the liquid alloys $\mathrm{Ag}-\mathrm{Bi}^{(5)}$ and $\mathrm{Ag}-\mathrm{Pb}^{(6)}$ as shown in Figs. 17 and 18.

If the constituent atoms of the alloy are nearly the same atomic volume, the heat of mixing gives a parabolic dependence of composition, but if there is a marked difference between the atomic volume, the curve of the

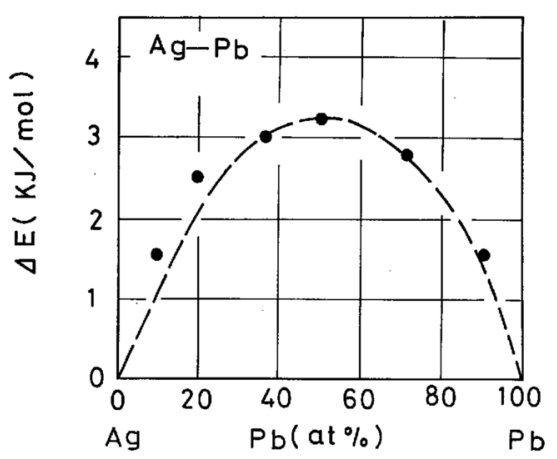

Fig. 17 Heat of mixing for liquid $\mathrm{Ag}-\mathrm{Pb}$ alloys at $1000^{\circ} \mathrm{C}$. The Solid circles indicate the observed values by Itagaki and Yazawa ${ }^{(6)}$ and the broken line the calculated one. 


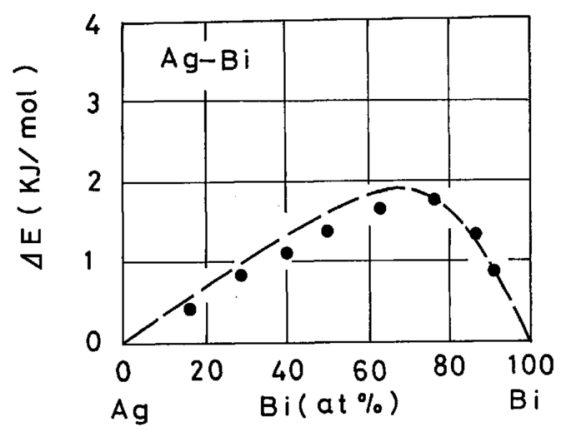

Fig. 18 Heat of mixing for liquid $\mathrm{Ag}-\mathrm{Bi}$ alloy at $1000^{\circ} \mathrm{C}$. The solid circles indicate the observed values by Uemura and Takeuchi and the broken line the calculated one.

heat of mixing deviates from the parabolic form. The heat of mixing $\Delta E$ in this case has been given by one of the present authors ${ }^{(1)}$ as follows :

$$
\Delta E=\frac{C x(1-x) w_{A B}}{[1+(C-1) x]^{2}},
$$

where $C$ denotes the volume ratio of the constituent atoms and $w_{A B}$ the energy of mixing. In the case of the liquid $\mathrm{Ag}-\mathrm{Pb}$ alloy, the heat of mixing calculated from eq. (9) with $C=$ 0.9 and $w_{A B}=13.3 \mathrm{~kJ} / \mathrm{mol}$ is in good agreement with the observation as shown in Fig. 17. In the case of the liquid $\mathrm{Ag}-\mathrm{Bi}$ alloy, the curve calculated for $C=0.5$ and $w_{A B}=7.2 \mathrm{~kJ} / \mathrm{mol}$ has a broad peak of heat absorption in the neighborhood of $70 \% \mathrm{Bi}$, in good agreement with the observation as seen in Fig. 18.

For the liquid alloys Ag-In, $\mathrm{Ag}-\mathrm{Sn}$ and $\mathrm{Ag}-\mathrm{Sb}$, the observed thermoelectric power and magnetic susceptibility are in disagreement with that calculated on the basis of the simple model described above. The magnetic susceptibility curve plotted against the alloy composition has a diamagnetic increase near the concentrations of $25 \%$ In in the liquid $\mathrm{Ag}-\mathrm{In}$ alloy, $20 \% \mathrm{Sn}$ in the liquid $\mathrm{Ag}-\mathrm{Sn}$ alloy, and $12 \% \mathrm{Sb}$ in the liquid $\mathrm{Ag}-\mathrm{Sb}$ alloy. Such diamagnetic increases in susceptibility correspond to peaks of evolution of heat in the curves of heat of mixing which have been measured by Itagaki and Yazawa $^{(6)}$ and Uemura and Takeuchi ${ }^{(5)}$. Accordingly, in these liquid alloys, part of the constituent atoms are distributed randomly while the others coalesce into small groups by a sort of covalent bonding. The composition of these atomic groups is considered to be nearly the same as that corresponding to the peak of the heat evolution described above. If these atomic groups are formed, a large diamagnetic susceptibility is expected to be present. The coalesced atomic group is not so large but is rather similar to a molecule of the composition $A_{m} B$. Since the magnitude of the peak of heat evolution in the heat of mixing curve is of the order of several kilo-joule/mol, the number of electrons associated with the bonding of molecule is considered to be less than the saturation value necessary for the complete covalent bonding of the molecule described above. Such a molecule has been referred to as the pseudomolecule ${ }^{(1)}$ since it differs from a real molecule.

Anomalous behavior of the thermoelectric power in the liquid alloys $\mathrm{Ag}-\mathrm{In}, \mathrm{Ag}-\mathrm{Sn}$ and $\mathrm{Ag}-\mathrm{Sb}$ are also considered to be caused by the existence of such a pseudo-molecule.

In the forthcoming paper, the calculated results of the thermoelectric power will be reported by taking the formation of the pseudomolecule into account.

\section{Conclusions}

(1) The thermoelectric power and magnetic susceptibility have been measured for liquid alloys $\mathrm{Ag}-\mathrm{In}, \mathrm{Ag}-\mathrm{Sn}, \mathrm{Ag}-\mathrm{Pb}, \mathrm{Ag}-\mathrm{Bi}$ and Ag-Sb.

(2) The thermoelectric power $S$ is calculated for the binary mixture of hard spheres of different diameters in the gas atmosphere of conduction electrons using the pseudopotential proposed by Borchi et al.

(3) The thermoelectric powers calculated for the liquid alloys $\mathrm{Ag}-\mathrm{Pb}$ and $\mathrm{Ag}-\mathrm{Bi}$ are in good agreement with the observations. But calculated results for the other liquid silver alloys are in disagreement with the experimental results.

(4) Both the heat of mixing and the magnetic susceptibility for the liquid alloys $\mathrm{Ag}-\mathrm{Pb}$ and $\mathrm{Ag}-\mathrm{Bi}$ evaluated under the above assumption show good agreement with the observations.

(5) The magnetic susceptibility curve for the other silver alloys has a diamagnetic increase 
in the composition range of 75 to $85 \% \mathrm{Ag}$, which corresponds to a peak of the heat evolution in the heat of mixing. Such a diamagnetic increase can be considered to be caused by the formation of the pseudomolecule.

\section{REFERENCES}

(1) S. Takeuchi, O. Uemura and S. Ikeda: Sci. Rep Ritu., 25 (1974), 41.

(2) E. Schürman and A. Kaune: Z. Metallk., 56 (1965), 575.

(3) S. Takeuchi, K. Suzuki, M. Misawa, F. Ito and K. Murakami: Sci. Rep. Ritu., 25 (1974), 56.

(4) S. Takeuchi and K. Murakami: Sci. Rep. Ritu., 25 (1974), 73.

(5) O. Uemura and S. Takeuchi: J. Japan Inst. Metals, 37 (1973), 252.

(6) K. Itagaki and A. Yazawa: J. Japan Inst. Metals, 32 (1968), 1294.

(7) J. E. Enderby and R. A. Howe: Phil. Mag., 17 (1968), 923.

(8) R. A. Howe and J. E. Enderby: Phil. Mag., 16 (1967), 467.
(9) A. S. Marwaha: Proc. 1st Inter. Conf. on Properties of Liquid Metals, 1966, Adv. in Phys., 16 (1967), p. 617.

(10) N. E. Cusack and P. W. Kendall: Proc. Soc., 72 (1958), 898.

(11) A. S. Marwaha and N. E. Cusack: Phys. Lett., 22 (1965), 556.

(12) R. Blakeway: Phil. Mag., 18 (1969), 965.

(13) S. Takeuchi and M. Matsuura: Trans. JIM, 17 (1976), 717.

(14) J. M. Ziman: Phil. Mag., 11 (1965), 153.

(15) T. E. Faber and J. M. Ziman: Phil. Mag., 11 (1965), 153.

(16) N. W. Ashcroft: J. Phys. C., 1 (1968), 232.

(17) J. E. Moriarity: Phy. Rev. B, 1 (1970), 1363.

(18) E. Borchi and S. De. Gennaro: Phys. Lett., 32A (1970), 301.

(19) O. Dreirach, R. Evans, H-J. Günterrodt and H-U. Künzi: J. Phys. F, 2 (1972), 709.

(20) G. Cubiotti, E. Donato, E. S. Giuliano and R. Ruggeri: Nuovo Chm., 9B (1972), 709.

(21) A. O. E. Animal: Phy. Rev. B, 8 (1973), 3542.

(22) A. Roll and E. Uhr: Zeit. Met., 50 (1959), 159. 